\title{
Control Judgements across the Lifespan
}

\author{
Alexander Grob \\ University of Berne, Switzerland \\ Todd D. Little \\ Yale University, USA \\ Brigitte Wanner
}

Max Planck Institute for Human Development, Germany

Given the inconsistent findings in the literature, we examined age-cohort differences in various personal control judgements over the lifespan $(N=1623$; ages 14-85). For three distinct life domains (personal, social, and societal), participants rated their amount of personal control, the goal importance, the degree of control striving, and, in comparison with sameaged peers, their relative control in each domain. Within this broad lifespan range, the developmental trends showed, as expected, different trajectories depending upon the type of control dimension and the nature of the life domain. The differential nature of these age-cohort trends have important implications for understanding the inconsistent findings reported in the literature, namely, that depending on the nature of the life domain, the type of control dimension, and the age range tested, the trajectories can either increase, decrease, or remain stable. These trends are discussed with reference to various metatheoretical perspectives on lifespan development and control-related judgements.

Requests for reprints should be sent to either Alexander Grob, Institute of Psychology, University of Berne, Muesmattstrasse 45, CH-3000 Berne 9, Switzerland; e-mail: Alexander. Grob@psy.unibe.ch, or to Todd D. Little, Department of Psychology, Yale University, PO Box 208205, New Haven, CT 06520-8205, USA; e-mail: Todd.Little@Yale.edu.

The research was supported in part by the Swiss National Science Foundation (Project No. 11 36228.92), the Swiss Society for Humanities, and the Max Planck Society. Much of this work was conducted while the second author was a research scientist at the Max Planck Institute for Human Development in Berlin, Germany. The authors would like to thank the numerous colleagues for their valuable input. Parts of these data were represented at XIVth meetings of the International Society for the Study of Behavioral Development held in Quebec City, Canada, 1996.

(c) 1999 The International Society for the Study of Behavioural Development 
Control perceptions (e.g. beliefs about the likelihood of achieving a desired goal) are fundamentally important aspects of one's psychological world because of their action-guiding influence (Brandtstädter, 1997; Flammer, 1990; Lachman, 1986; Skinner, 1995; White, 1959). Individuals who are low in psychological control often do not initiate specific actions toward a goal, whereas those who possess a sense of control do (Bandura, 1997). Having a positive sense of personal control increases the probability of reaching desired outcomes, and, in turn, subsequent mastery experiences strengthen a positive sense of personal empowerment (i.e. feelings of personal control and well-being). Unfortunately, such cyclic processes can have negative loops, too. A lack of psychological control lowers the probability of gaining desired outcomes which, in turn, can undermine the basis for trusting in one's action capabilities. In this cross-sectional study, we examine the lifespan trajectories of such control-related judgements.

\section{Developmental Trajectories Described in the Literature}

Recent reviews of cross-sectional and longitudinal research on developmental changes in control perceptions have reported contradictory findings (see Kogan, 1990; Lachman, 1986; Lumpkin, 1986; Welch \& West, 1995). For instance, lifespan increases in personal control have been reported (Lachman, 1985; Siegler \& Gatz, 1985), whereas other studies have indicated lifespan decreases in personal control (Berry, West, \& Dennehey, 1989; Box \& Peck, 1981; Hertzog, Hultsch, \& Dixon, 1989; Molinari \& Niederhe, 1984; Rebok \& Balcerak, 1989). And, adding to the confusion, still other studies have reported no variations in control-related perceptions across the lifespan (Brandtstädter \& Rothermund, 1994; Lachman, 1986; Nehrke, Hulicka, \& Morganti, 1980; Reker, Peacock, \& Wong, 1987).

In an effort to rectify some of these seeming contradictions, we take into account three considerations that may contribute to the different trends across the life course: (a) the domain specificity of control perceptions (Berry \& West, 1993; Lachman, 1986); (b) the type of control conceptualisation (i.e. the various dimensions of control perceptions; Skinner, 1996); and (c) the breadth of the studied age ranges (Baltes, Reese, \& Nesselroade, 1977).

Domain Specificity. In general, people strive for control in domains that are personally relevant (Berry \& West, 1993; White, 1959). The more relevant the life-domain goal, the more important it is to have a sense of psychological control over it. Moreover, with respect to various personal and societal constraints, the relevance of goals changes over the lifespan 
(Hagestad, 1990; Mayer, 1986). For example, Nurmi (1992) has suggested that changes in the relevance of goals reflect major developmental tasks for individuals of a given age. In support of this idea, he and his colleagues (Nurmi, 1994; Nurmi, Pulliainen, \& Salmela-Aro, 1992) found that physical health became increasingly important in late and very late adulthood, whereas young adults were more concerned about themselves and their friends. This idea that psychological control is domain specific is common to numerous perspectives (see also Lachman, 1986), including self-efficacy theory (Bandura, 1997), and various action-related theories (Brandtstädter, 1997; Flammer, 1990; Frese \& Sabini, 1985, Little, 1998; Skinner, 1995).

Relatedly, Nurmi et al. (1992) also showed an interesting interplay between the importance of health-related goals and concerns on the one hand, and the levels of personal control (internality) on the other. Across the lifespan, health became more important, but perceived personal control of health-related goals and concerns decreased steadily. The same pattern was demonstrated for societal concerns (i.e. global issues, war). The authors offered two interpretations of these age differences. The first focused on the lifespan related changes in people's opportunity to influence domains of life and the other focused on the possibility that older people make more accurate appraisals than younger adults. Importantly, both interpretations assume domain specificity of control judgements.

In concert with these theoretical perspectives, we also assume that personal control perceptions vary across different life domains. In this study, we examine specific instances of life goals in three life domains that were general enough to be relevant across the lifespan, but specific enough to represent distinct life domains; personal, social, and societal. Although the instances within each domain are not exhaustive, they are generally representative of the possible concerns within each domain. Theoretically, the three domains vary in the degree to which control potential is determined by the self or co-jointly by the presence of others, either real or imagined. Specifically, for the personal domain we used physical appearance which is mainly determined by the individual himself or herself. For the social domain, we used maintaining harmony with a significant other which is mainly determined within a dyad or small group. Last, for the societal domain, we used environmental concerns which is mainly determined by the collaboration of very many others (imagined or otherwise).

Control Conceptualisation. As Skinner (1996) has outlined, many control constructs exist in the literature. For this study, we used four broadly selected control dimensions: general control expectancy, goal 
importance, control striving, and comparative control. These control constructs have been utilised and validated in prior longitudinal (Grob, Flammer, \& Wearing, 1995) and cross-cultural research (Grob, Little, Wanner, Wearing, \& Euronet, 1996).

The first component, general control expectancy, reflects the cognitive expectation of the extent to which a person feels personally empowered (i.e. in control). This component of control is comparable to self-efficacy in Bandura's (1997) conceptualisation and is a central feature in general action-theory perspectives of psychological control (Little, 1998; Skinner, 1995, 1996).

The second component of psychological control is the importance or valuation of the goal situation. This component reflects the anticipated reinforcement value of a given outcome. In a broad-based cross-cultural study that we and our colleagues conducted (Grob et al., 1996), for example, the appraised importance of relevant life goals showed substantial differences between Eastern European and Western European adolescents. We interpreted these differences from a contextual perspective, suggesting that the higher control appraisal of Eastern European adolescents relative to their Western European peers may have emanated from the opportunities associated with the dramatic changes in the various Eastern European contexts. Viewing age as a life phase context, various personal resources and age context constraints could, similarly, predicate changes in the appraised importance or value of attaining goals in different life domains (Ryan, Sheldon, Kasser, \& Deci, 1996).

The third component of psychological control that we examine is the degree of control striving within the goal domain. This component reflects the degree of investment in a goal (Brandtstädter, 1997; Heckhausen \& Schultz, 1995). That is, wanting or striving for control reflects the degree to which a life goal is endorsed within one's personal motivational system (Ryan et al. 1996).

Finally, the fourth control dimension that we included in the present study is comparative control. In contrast to the other three control dimensions, relatively little work has examined peer-referenced control judgements. Given the importance of social comparison processes throughout the lifespan (Heckhausen \& Krueger, 1993), the relative perception of control (i.e. amount of control relative to same-aged peers) may yield quite different developmental patterns in relation to absolute ratings of control expectancy, control striving, or the appraised importance of control within a given life domain.

Each of these four components of psychological control reflect distinctive aspects of a larger control system that contains many interconnected links (e.g. intention, action, and evaluation; Skinner, 1995, 1996). For this study, we focus on two basic features of the control 
judgements. First, we examine the lifespan similarities (or differences) in the correlational nexus among the four control components, both within and between life domains, and second, we identify and compare their mean-level developmental trends.

The Studied Age Range. The contradictory findings in lifespan control research may also emanate from limited age ranges (Baltes et al., 1977). If, for example, a given control conception is distributed as an inverted Ucurve across the lifespan and it is tested with only two or three samples, one might easily find an increase, a decrease, or no age-related variation, depending on the specific ages, or points along the trajectory, that have been selected. Not uncommonly, empirical work that has been reported is based on such limited age ranges. For example, Lachman (1985) compared only two age cohorts (19-21 years old vs. 69-75 years old) and reported heterogeneous results. Similarly, Siegler and Gatz (1985) studied personal control of adults aged 46-69 and reported a decrease with age. In our view, both a broad age span and multiple consecutive age groups must be studied in order to make valid and reliable conclusions about the lifespan age trends in control-related judgements.

\section{Specific Goals and Hypotheses of the Current Study}

The specific goals of this study are to examine: (a) the underlying correlational nexus; and (b) the mean-level developmental trajectories of four control-related judgements (control expectancy, goal importance, control striving, and comparative control) across three lifespan relevant domains (personal, social, and societal), using cross-sectional samples spanning the age range from 14 to 85 years.

Correlational Patterns We had two related hypotheses regarding the correlational patterns among the constructs. First, we expected the four control judgments within each domain to show similar relations to one another, but second, we expected the three domains in which the judgements are made to show distinct patterns of discrimination (i.e. domain specificity).

The first of these two hypotheses concerns the psychological meaning of the control concepts within each domain and across each age-cohort. Specifically, we hypothesise that the four control-related concepts (i.e. control expectancy, goal importance, control striving, and comparative control) will show equivalent patterns of individual-differences relations in each of the three domains and in each age-cohort. This hypothesis refers to 
both: (a) the basic measurement properties (e.g. measurement equivalence; Little, 1997); and (b) the latent correlational relations among the respective control concepts. We anticipate similar correlation patterns under the assumption that the individual-difference relations reflect the normative psychological interrelations among the control constructs (i.e. general world views about the relations among these control constructs would not change across domains or the lifespan; see also Grob et al., 1996).

The second of these two hypotheses concerns the specificity of the life domains. As mentioned, the three domains vary in the degree to which control potential is determined by the self or co-jointly by the presence of others, either real or imagined. Therefore, we expected the highest degree of discrimination among the control judgements to emerge between the personal and societal domains. For the social domain, we anticipated moderate links among the control judgements with both the personal and the societal domains.

Mean-level Trajectories. Our third expectation regarding the control judgements focuses on the relative age-cohort differences in the meanlevels among the types of judgements and life domains. Because the specific shapes of the trajectories cannot be convincingly articulated in an a-priori manner (given the contradictory findings and the numerous theoretical perspectives that can be invoked), we anticipated considerable variations among the 12 developmental trajectories (i.e. for the four control dimensions within the three life domains).

\section{METHOD}

\section{Participants}

We combined data from two prior studies with overlapping topics: the Berne longitudinal study on adolescence (Flammer, Grob, \& Lüthi, 1989; Grob et al., 1995) and a study of adults' control attributions and attitudes toward the environment (Grob, 1991, 1995). From the Berne longitudinal study on adolescence, participants from the first measurement point were chosen $(n=1048)$. These participants were selected from their classes according to the Swiss schooling system which has nine years of obligatory schooling. For the 7 th to 9 th grades (obligatory schooling years), 43\% came from lower track schools (primary schools) and 57\% were in higher track schools (secondary schools). The participants in the post-obligatory schooling years came from Gymnasiums and teachers' training colleges (45\%), and professional schools (55\%). Of all adolescents, half came from urban and suburban areas and half from rural areas. According to the Swiss federal census data, the distribution of parents' occupations was 
unbiased. For example, 55\% of the adolescents' mothers were homemakers (for details see Grob et al., 1995). Supplemental analyses of selectivity effects revealed negligible and unsystematic effects.

The adult sample consisted of 583 participants. The adults were randomly selected from the Berne telephone directory and equally drawn from rural and urban areas. As indicated by the Swiss federal census data, the adult sample was also generally unbiased; however, supplemental selectivity analyses indicted that our sample was slightly better educated than average (for details see Grob, 1995).

For some of our analyses (see later), we formed 12 age groups (the indicated percentage is the percentage of females for each group): 14 $(n=91,49 \%), 15(n=191,53 \%), 16(n=158,42 \%), 17(n=156,45 \%)$, $18(n=217,58 \%), 19(n=227,54 \%), 25(21-29$ years, $n=183,53 \%)$, $35(30-39$ years, $n=166,69 \%), 45(40-49$ years, $n=95,67 \%), 55(50-59$ years, $n=44,61 \%), 65(60-69$ years, $n=59,59 \%)$, and 80 (70-89 years, $n=36,74 \%$ ). Overall, $55 \%$ of the participants were female and $45 \%$ were male. Note that the asymmetry in the age-groupings does not bias our analyses because it is taken into account.

\section{Instrument}

For this study, we analysed the 18 items that were identical across these two data sets. These items, which come from an established questionnaire on control perceptions (Lüthi, Grob, \& Flammer, 1989), assess personal control for everyday situations in the personal, social, and societal domains. The personal domain focuses on personal appearance, the social domain focuses on maintaining harmony within a close relationship (partner, spouse, parents), and the societal domain focuses on a natural environmental problem (i.e. the demise of forests due to environmental pollution). For each domain, participants responded to six questions on a 5-point scale $(\mathrm{X}=$ domain):

1 Amount of perceived actual control: "Indicate to what extent you can influence X".

2 Amount of expected personal control in the future: "Indicate to what extent you will be able to influence X in five to ten years" (for adolescents, in three to five years).

3 Importance of domain: "On the whole, how important is X to you?".

4 Importance of control: "On the whole, how important is it to you to influence X?".

5 Striving for control: "Do you try to have more influence on X?". 
6 Personal control in comparison with others: "Others your age may also be concerned with $\mathrm{X}$. Compare the influence you have on $\mathrm{X}$ with the influence they have on $X^{\prime \prime}$.

In this framework, the first 2 questions reflect personal control expectancy, or the amount of control attributed to oneself, the next 2 questions refer to the goal importance, or appraised importance of the domain. Question 5 assesses the control striving and question 6 assesses the comparative control (for details, including reliability and validity information, see Grob, 1991, 1995; Flammer et al., 1989).

\section{Analytical Procedures}

For the primary analyses, we used multiple-group mean and covariance structures (MACS) procedures (Little, 1997) with LISREL (Jöreskog \& Sörbom, 1989). MACS procedures are particularly relevant for our study because they provide numerous research advantages such as corrections for measurement errors (i.e. disattenuation), explicit tests of the crossgroup comparability of the constructs (i.e. measurement equivalence), inclusion of covariates to control for possible confounding effects, and a powerful framework for hypothesis testing (Little, 1997). More specifically, in addition to a variable representing gender, we entered the 18 indicators of the 12 constructs (4 control constructs per domain) into a 12-group MACS model in order to: (a) test the measurement equivalence of the constructs across each age-cohort and life domain; (b) confirm the domain specificity of the control constructs; and (c) model the age-related similarities and differences in the latent correlational structure. We used the comparative fit index (CFI), the incremental fit index (IFI), and the root-mean squared error of approximation (RMSEA) to assess model fit.

To model the age-related similarities and differences in the latent correlational structure we used nested-model comparisons. Specifically, because a MACS analysis is based on maximum-likelihood estimation, the log-likelihood ratio (i.e. the pseudo chi-squared value, $\chi^{2}$ ) from such analyses allows us to conduct direct statistical tests and extensive comparisons of the correlations among the constructs. Such tests are conducted using nested-model comparisons of the $\chi^{2}$ values. In particular, a model in which the latent correlations are estimated without any constraints or restrictions is compared with a model in which one or more theoretically defined constraints or restrictions are made. The differences in the $\chi^{2}$ values between these two models is also distributed as a $\chi^{2}$ (i.e. $\Delta \chi^{2}$ ) with degrees of freedom equal to the differences in the respective model's degrees of freedom $(\Delta d f)$. If the $\Delta \chi^{2}$ is significant, it indicates that one or more constraints or restrictions are untenable and that the null 
hypothesis of no difference is rejectable (see e.g. Little, 1997; Little \& Lopez, 1997, for empirical examples of this procedure). The advantages of this approach are that relations among the constructs and across the agecohort groupings can be tested and represented in a very parsimonious manner.

Finally, for the mean-level analyses, we used standard regression techniques to compare the intercept and slope differences for the age trends and to plot the trajectories on a nonarbitrary scale of measurement. Similar to the correlational analyses, we used nested-model comparisons to examine the similarities and differences in these trajectories. For these comparisons, we used the $F$-ratio to evaluate significance (see Little \& Lopez, 1997). We coded the 5-point scales such that zero reflects the conceptual mid point.

\section{RESULTS}

We present the results in three parts. First, we compare the dimensional validity and measurement equivalence of the control constructs across each life domain and age cohort. Second, we evaluate the age-related similarities and differences in the structure and domain specificity of the control constructs. Third, we evaluate the age- and cohort-related differences in the mean-level trajectories.

\section{Dimensional Validity and Measurement Equivalence of the Control Judgements}

First, to test the dimensional validity of the constructs we specified a confirmatory factor model (12 constructs) for each of the age-cohorts, with gender included as a covariate. The fit of this unconstrained (freely estimated) measurement model was very acceptable $(\mathrm{CFI}=.93, \mathrm{IFI}=.94$, RMSEA = .024). This model assesses and strongly supports the general theoretical structure (i.e. dimensional validity) among the 12 constructs in each group. That is, the confirmatory model positing four discrete control judgements for each of the three domains was very tenable in each group, particularly because no residual correlations or dual factor loadings were needed and because the correlations among the constructs were of only moderate magnitude (see later). We mention here that the gender effects were minimal. Only 8 of the 192 effects (4\%) reached the .01 level and in all cases the effect was on a control importance judgement with females offering higher ratings of importance than their male peers ( 7 of the effects were between the ages of 14 and 18).

Second, to test the measurement equivalence or comparability of the four control aspects across the three domains and 12 age-cohorts, we invoked the constraint of metric invariance. That is, we equated the 
respective construct loadings and intercepts across domains and agegroups. This model showed nearly identical quality of fit $(\mathrm{CFI}=.91$, $\mathrm{IFI}=.91, \mathrm{RMSEA}=.027)$. Given the very minimal difference in fit between these two models (Little, 1997), we can proceed under the assumption that the four control constructs reflect discrete dimensions of psychological control with generally equivalent psychometric properties across the life domains and the 12 age-groupings.

\section{Structure and Domain Specificity of the Control Judgements}

Figure 1 displays the results of our nested-model tests of the age-cohort similarities and differences in the correlational relations among the four control constructs for each life domain. Importantly, these constrained correlations do not differ from the unconstrained, or freely estimated, correlations $\left[\Delta \chi^{2}(781, N=1623)=809.6, P=.23\right]$.

The most impressive result from these constrained analyses is that the correlations among the four control constructs were statistically the same both (a) across the three life domains and (b) across the 12 age cohorts. This expected outcome indicates that the correlational structure among the four control constructs is very robust and generalisable across the three life domains and the 12 age cohorts. As seen in Fig. 1, only Control Striving and Goal Importance showed a notable degree of overlap with $44 \%$ shared variance. The relations between Control Expectancy and Goal Importance showed approximately $18 \%$ overlap in each domain, whereas the remainder of the correlations reflected less than $10 \%$ overlap among the control constructs. This low degree of overlap among the four constructs further supports multidimensional conceptions of psychological control

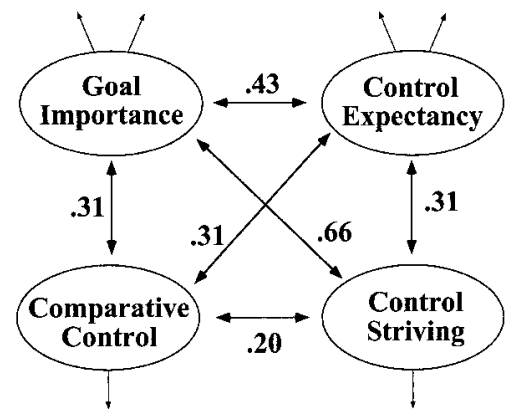

FG. 1. The equivalent correlational structure among the four control-related judgements (a) in each of the three life domains (personal, social, and societal) and (b) across the 14 agecohorts. Note: These constrained correlations do not differ significantly from the unconstrained correlations $\left[\Delta \chi^{2}(781, N=1623)=809.6, P=.23\right]$. 
(Little, 1998; Skinner, 1996). Notably, the identical nature of the structure among the control constructs within each domain and across each agecohort highlights the robust nature of the psychological meaning of these constructs.

In support of our hypothesis regarding the domain specificity of control judgements, a high degree of discrimination emerged between the domains. In particular, the four control-related constructs in the societal domain and the same four constructs in the personal domain showed very little overlap, as expected. Of the 192 possible $r$ s between these two domains, the median was 0 (in fact, $95 \%$ were within \pm .12 ). Table 1 shows a general summary of the age-partialed correlations across each of the four constructs and across the three domains. Also as expected, the constructs showed generally positive but small correlations between the societal and social domains (median $r=.06 ;<5 \%$ were zero or slightly negative), and between the social and personal domains (median $r=.12 ;<5 \%$ were zero or slightly negative). The low correlations of the control constructs across the three life domains provides strong evidence for the domain specificity of psychological control. Also, the systematic differences in the betweendomain correlations (i.e. generally zero correlations between the personal and societal domains and generally positive correlations between the personal and social domains, and between the social and societal domains) supports our expectation that the social domain shares some commonality

TABLE 1

Age-partialed Cross-domain Correlations between the Constructs in the Overall Sample

\begin{tabular}{|c|c|c|c|c|c|c|}
\hline Domain & \multicolumn{2}{|c|}{ Construct } & $A$ & $B$ & $C$ & $D$ \\
\hline & & & & Persor & omain & \\
\hline \multirow[t]{4}{*}{ Social } & (A) & Control Expectancy & .32 & .11 & .17 & .09 \\
\hline & (B) & Comparative Control & .16 & .26 & .13 & .04 \\
\hline & (C) & Goal Importance & .10 & .12 & .22 & .12 \\
\hline & (D) & Control Striving & .11 & .13 & .19 & .20 \\
\hline \multirow[t]{5}{*}{ Societal } & (A) & Control Expectancy & .12 & .07 & .00 & .02 \\
\hline & (B) & Comparative Control & .04 & .05 & -.02 & -.01 \\
\hline & (C) & Goal Importance & -.03 & -.01 & .00 & -.02 \\
\hline & (D) & Control Striving & -.02 & .06 & -.03 & .06 \\
\hline & & & \multicolumn{4}{|c|}{ Social Domain } \\
\hline \multirow[t]{4}{*}{ Societal } & (A) & Control Expectancy & .16 & .06 & .07 & .05 \\
\hline & (B) & Comparative Control & .06 & .09 & .07 & .07 \\
\hline & (C) & Goal Importance & .12 & .08 & .31 & .17 \\
\hline & (D) & Control Striving & .05 & .07 & .22 & .20 \\
\hline
\end{tabular}

Note: The linear, quadratic, and cubic effects of age have been partialed from the correlations. Although $P<.01$ if $r \leq|.10|$, effects sizes are negligible. 
with both personal and societal issues, but that personal and societal issues are quite independent domains.

\section{Age-Cohort Trajectories}

The modelled trends for the age-related comparisons across the four control constructs and three life domains are presented in Fig. 2. Recall that values greater than zero indicate generally above average judgements (i.e. a positive amount), whereas values below zero indicate generally below average judgements (i.e. a negative amount). As with the correlational structure, these constrained age-cohort trends do not differ from the unconstrained trends $[F(31,19427)=1.21, P=.20]$ (for comparative purposes, the raw means and standard deviations are in Table 2). In Fig. 2, the nonidentical and nonoverlapping trends differ from one another (for all $F$-tests, $P<.01$ ) and all estimated parameters of a given trend are significantly different from zero (for all $t$-tests, $P<.01$ ).

Consistent with our expectations, the different control constructs assessed across the three life domains showed substantially different lifespan trajectories. Notably, these trends accounted for $22 \%$ of the agerelated variance.

Control Expectancy. Across the lifespan, the amount of perceived control in the personal and social domains was rated higher than in the
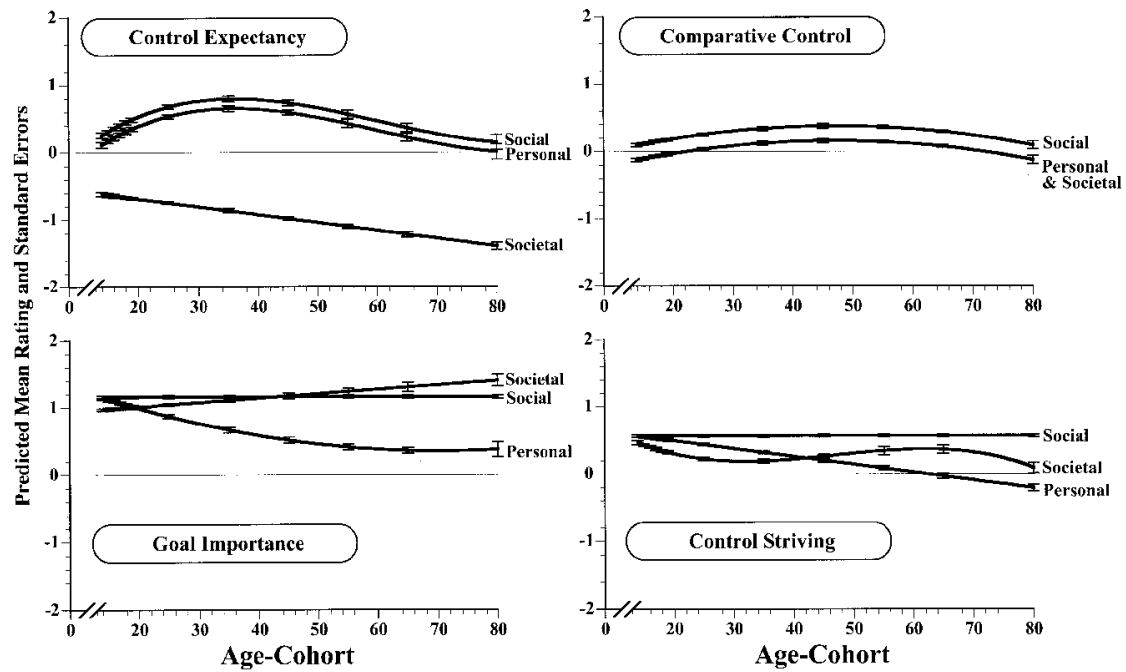

FG. 2. Developmental trajectories of the four control-related judgements across the three life domains. Note: These constrained trends do not differ significantly from the freely estimated trends $[F(31,19427)=1.21, P=.20]$. 
TABLE 2

Means (and Standard Deviations) for the Four Control Judgements in Each Life

Domain

\begin{tabular}{llllllllllll}
\hline \multicolumn{11}{c}{ Age-Cohort } \\
\cline { 2 - 6 }
\end{tabular}

Personal Domain

Control Expectancy

$\begin{array}{lllllllllllll}M & 0.50 & 0.52 & 0.52 & 0.44 & 0.62 & 0.58 & 0.75 & 0.51 & 0.67 & 0.43 & -0.05 & -0.21\end{array}$

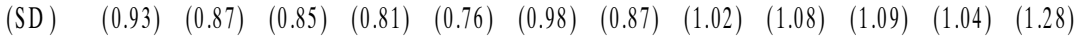

Comparative Control

$\begin{array}{lllllllllllll}M & -0.02 & 0.10 & 0.15 & -0.05 & -0.01 & 0.05 & 0.10 & 0.25 & 0.31 & -0.11 & -0.03 & -0.01\end{array}$

$\begin{array}{llllllllllll}(\mathrm{SD}) & (1.11) & (0.92) & (1.01) & (1.07) & (1.02) & (0.91) & (0.88) & (0.94) & (1.08) & (0.94) & (1.18)\end{array}$

Goal Importance

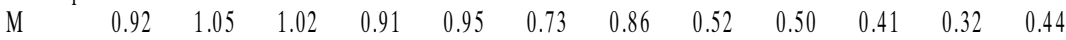

$\begin{array}{lllllllllllll}(\mathrm{SD}) & (0.87) & (0.77) & (0.91) & (0.75) & (0.93) & (0.93) & (0.84) & (0.95) & (1.07) & (0.99) & (1.08) & (1.17)\end{array}$

Control Striving

$\begin{array}{lllllllllllll}M & 0.57 & 0.62 & 0.59 & 0.55 & 0.44 & 0.37 & 0.57 & 0.10 & 0.40 & 0.14 & -0.01 & 0.01\end{array}$

$\begin{array}{lllllllllllll}(\mathrm{SD}) & (0.84) & (0.95) & (0.87) & (0.81) & (0.84) & (1.04) & (1.01) & (1.05) & (1.19) & (1.28) & (1.22) & (1.22)\end{array}$

Social Domain

Control Expectancy

$\begin{array}{lllllllllllll}M & 0.44 & 0.57 & 0.60 & 0.63 & 0.76 & 0.75 & 0.97 & 0.82 & 0.58 & 0.59 & 0.29 & -0.05\end{array}$

$\begin{array}{lllllllllllll}(\mathrm{SD}) & (0.96) & (0.84) & (0.93) & (0.82) & (0.90) & (0.90) & (0.87) & (0.86) & (0.95) & (0.93) & (1.08) & (1.36)\end{array}$

Comparative Control

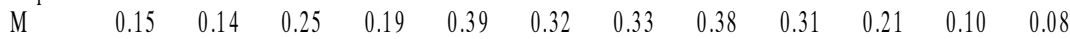

$\begin{array}{lllllllllllll}(\mathrm{SD}) & (1.03) & (0.93) & (0.87) & (1.01) & (1.10) & (1.06) & (0.93) & (0.94) & (0.99) & (0.98) & (1.17) & (1.05)\end{array}$

Goal Importance

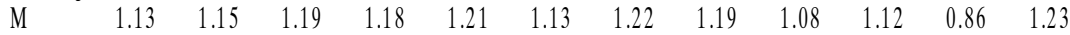

$\begin{array}{lllllllllllll}(\mathrm{SD}) & (0.88) & (0.78) & (0.87) & (0.78) & (0.89) & (0.87) & (0.81) & (0.90) & (0.83) & (0.84) & (1.01) & (0.93)\end{array}$

Control Striving

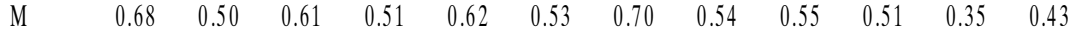

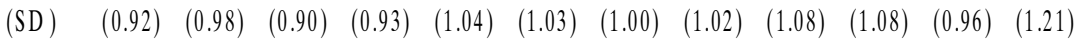

Societal Domain

Control Expectancy

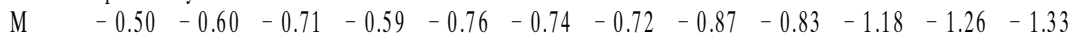

$\begin{array}{llllllllllllll}(\mathrm{SD}) & (0.92) & (1.02) & (0.97) & (1.00) & (0.93) & (0.91) & (0.96) & (1.00) & (0.92) & (0.87) & (0.81) & (0.73)\end{array}$

Comparative Control

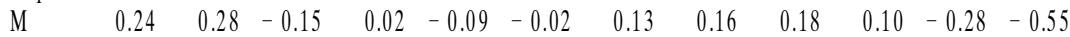

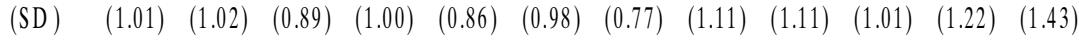

Goal Importance

$\begin{array}{lllllllllllll}M & 1.00 & 1.07 & 1.05 & 0.94 & 1.08 & 1.01 & 1.01 & 1.22 & 1.23 & 1.12 & 1.23 & 1.33\end{array}$

$\begin{array}{lllllllllllll}(\mathrm{SD}) & (0.99) & (0.89) & (0.97) & (1.01) & (1.00) & (0.94) & (0.87) & (0.89) & (0.77) & (0.93) & (0.84) & (0.84)\end{array}$

Control Striving

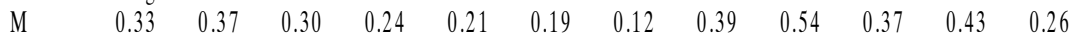

\begin{tabular}{lllllllllllll}
$(\mathrm{SD})$ & $(1.07)$ & $(0.95)$ & $(0.94)$ & $(1.04)$ & $(1.08)$ & $(1.05)$ & $(0.89)$ & $(0.98)$ & $(0.87)$ & $(1.01)$ & $(1.01)$ & $(1.17)$ \\
\hline
\end{tabular}


societal domain. Although the slopes for the personal and social domains did not differ $(P=.20)$, their starting points (intercepts) differed $(P<.01)$. As depicted in Fig. 2, the paths showed an increase from adolescence to about the third life decade, followed by a decrease into old age with some slowing after around age 60. The trend for societal-environmental concerns, in contrast, showed a steady linear decrease, but, in terms of absolute levels, was rated quite low across each age-cohort.

Goal Importance. The trends for goal importance differed substantially from those of control expectancy. Except in adolescence, the social and societal domains were rated as more important than the personal domain. During adolescence, all three domains were evaluated as generally equally important. Social relations were viewed as equally important across the lifespan, whereas the importance of societal concerns increased, surpassing the importance of the social domain around age 55. In contrast to the social and societal domains, the trajectory for the personal domain showed a pronounced decrease from adolescence to about age 65 , followed by a general stability into old age.

Control Striving. As indicated in Fig. 2, participants from all age groups reported that they do, indeed, strive for control in each domain; only the personal domain showed generally neutral values after about age 65. Importantly, the nature of the trends differed across the three domains. Although all three trends started at about the same level in adolescence, control striving in the personal domain decreased linearly whereas, in the social domain, control striving remained steadily positive. In contrast, the trend for the societal domain followed a strict cubic function. Control striving was high in adolescence, low in young adulthood, high again in later adulthood, and, finally, low again in old age.

Comparative Control. A notable outcome for comparative control is the replication of the finding that people generally overestimate their personal control in comparison to the control they attribute to their peers, although, in adolescence and old age, comparative control in the personal and societal domains was rated as slightly lower than that of one's peers. Notably, the trends in each domain were strictly quadratic, and only the intercept for the social domain differed among the components of these trends $(P<.01)$.

\section{DISCUSSION}

Our main goal was to investigate how various control-related judgements change across the lifespan because the current literature is unclear about 
what this developmental variation looks like. Some studies show a general increase, some a decrease, and still others show no age changes. To address these inconsistencies, we offered three considerations as possible reasons for the conflicting results: (a) the domain specificity of control judgements; (b) the type of control construct; and (c) the age-range examined. A unique contribution of this study is that all three of these considerations were explicitly integrated into a single study in order to determine the degree of consistency or inconsistency of lifespan changes in control judgements. By examining a broad age-range, we expected the age trends of a given control judgement to increase, decrease, or remain stable, but in meaningful and systematic ways across the three life domains and the four types of construct. At the same time, we also expected the basic interrelations among the control constructs to remain stable across agecohorts and life domains and to be differentiated according to life domain. All told, our findings strongly supported our hypotheses.

\section{General Interrelations between Control Judgements and Life Domains across the Lifespan}

Broadly speaking, a number of important features of the resulting age trends emerged. To begin, the correlational structure of the four components was very stable across the three life domains and 12 agecohorts. This finding highlights the robustness and generalisability of the interrelations between control judgements. In other words, the control judgements are discrete conceptions that have a consistent psychological interplay, or distance, between them. In addition, the constructs' low correlations between the three life domains highlights the distinctive, domain-specific, nature of the various control judgements.

Although the psychological locations of the control constructs are consistent across life domains and age-cohorts, their heights, or meanlevels were quite variable. Some general features of the mean-level relations deserve mention.

First, control striving in each domain was generally positive across the lifespan. That is, the motivational impetus of control striving appears to function positively across the lifespan. This result corroborates the assumption that primary control striving is stable and high across adulthood (H. Heckhausen, 1991; Heckhausen \& Schultz, 1995; White, 1959). However, the degree of striving for control differs with respect to domain, with greater control striving for social concerns, followed by personal and societal concerns.

Second, very pronounced differences emerged for control expectancy. Here, participants at all ages reported quite low amounts of control 
expectancy for societal concerns and, furthermore, this relative lack of perceived control decreased steadily with age. This pattern replicates the results of Nurmi (1994; Nurmi et al., 1992) who reported both low levels of personal control for societal concerns and a pronounced decrease across the lifespan. On the other hand, the expectation of attaining one's goals in the social and personal domains was quite high. Here, the age trends indicate that such expectations peak between the ages of 30 and 40 and decrease thereafter, but remain positive even in old age. This particular result sheds new light on the contradictory finding reported in the literature. In previous research, both high levels of generalised personal control (Brandtstädter \& Rothermund, 1994; Lachman, 1986; Reker et al., 1987) and high levels of control in the personal and social domains have been reported (Brandtstädter, Krampen, \& Heil, 1986; Nurmi et al., 1992); however, the same literature broadly indicates a decline in personal control across the lifespan. Our data, however, only partly corroborate these findings. More specifically, we found a substantial increase for control expectancy in the social and personal domains up to the middle of the third decade of life, thereafter, we found a general decline in control expectations into old age.

Third, although the three life domains were quite distinctive and heterogeneous, each was appraised as being important across the lifespan. In adolescence, they were judged as generally equally important; however, beginning with young adulthood, the importance of social and societal matters was much greater than for personal appearance; this latter result was also reported by Nurmi et al. (1992).

Finally, in accordance with many studies, our findings showed that people generally attribute more control to themselves than to their peers at each phase of the life course (Taylor \& Brown, 1994). This positive sense of comparative control increased in each domain from adolescence until the fifth decade, followed by a decrease into old age. Given that the domains were appraised as important across all ages and that people strive for control in these domains, the positive sense of comparative control may serve to maintain a positive sense of self (i.e. to facilitate the maintenance of positive self-esteem and well-being). In addition, the consistent trajectories across the three domains for comparative control suggest that social comparison processes are consistent, general, and relatively uniform influences across the lifespan.

At the outset, we acknowledge that because this study is cross-sectional in nature, the age-cohort trends that emerged may be related more to cohort effects than to age effects. The participants were born between 1905 and 1973. During this time, critical cultural, economic, and political events transpired. Because of such events, one could expect control judgements to show quite unsystematic trajectories across the different age-cohorts 
(Baltes et al., 1977). In our view, however, the emergent trends showed very meaningful and systematic trajectories. Although the systematic nature of the life-course trajectories does not suspend the general limits of a cross-sectional design, the limitations may be somewhat weakened.

A second limitation concerns the single situation per domain included. This restriction clearly limits the generalisability of our results. However, even though we assessed only these three situations, the results were very consistent with our expectations and showed a clear and systematic picture. Nonetheless, future studies should include more situations per domain and test, for example, whether the variability in the lifespan patterns across different situations within the same domain is higher than that across domains.

Finally, a third limitation that should be addressed in future research is our lack of outcome measures such as subjective perceptions of well-being or objective indexes of performance. Although control judgements have been identified as important correlates of well-being and performance across the lifespan (e.g. Baltes \& Baltes, 1990), examining the lifespan trajectories in these linkages would offer a clearer picture of how control judgements serve to regulate well-being and performance throughout the life course.

\section{Metatheoretical Perspectives on Lifespan Changes in Control Judgements}

Given the apparent multidimensional and domain-specific interplay of control judgements across the lifespan, broad perspectives are needed to interpret the nature of the emergent trends. Therefore, to better understand these findings, at least three metatheoretical considerations can be drawn upon to help interpret the various lifespan patterns.

First, all biophysical ageing is characterised by initial growth followed by decline and decay. For example, intellectual mechanics worsen over the lifespan (Lindenberger \& Baltes, 1994; Salthouse, 1991) and the same is true for physical fitness. From this perspective, after a phase of developmental growth, one would expect that control judgements would decrease during the remainder of the lifespan, especially for domains that require or involve considerable intellectual and physical resources. In our data, the trends for control expectancy in the social and personal domains appear to follow such a trajectory (see Fig. 2). For the personal domain (i.e. physical appearance), the trend is clearly consistent with the biophysical perspective. On the other hand, although the source of the trend in the social domain may be biophysical in nature (e.g. insufficient personal resources to invest in social relations), further research is needed 
to explore whether the parallel nature of the trends in the personal and social domains is due to a similar underlying process.

Second, Havighurst (1948) argued that in each life period a series of developmental tasks must be solved. Success leads to happiness and an increased probability of later success, whereas failure leads to unhappiness and an increased probability of future failure. From this viewpoint, personal control should neither decrease nor increase, only the life tasks with which the individual is faced should change. Here, assuming successive masteries of developmental tasks during the lifespan, control judgements should remain relatively stable after each new challenge even though the type of task would differ. In support of this view, both goal importance and control striving in the social domain remained stable across the lifespan (see Fig. 2). In other words, although the task requirements for maintaining harmonious social relations changes across the lifespan, their importance and the need to strive for them appear to remain stable developmental processes (see also Carstensen, 1995; Heckhausen \& Schulz, 1995).

Finally, the life-task perspective received refinements by Baltes and his colleagues (e.g. Baltes, 1987; Baltes \& Baltes, 1990; Heckhausen, Dixon, \& Baltes, 1989), who analysed lifespan development in metatheoretical terms (selection, optimisation, and compensation; Baltes \& Baltes, 1990). Similarly, but referring specifically to control judgements, Flammer (1990) proposed that psychological control fully emerges by about age 12 (coinciding with the structural end-marks of development; Piaget, 1947), but thereafter differentiates along life-phase relevant themes. These modified life-task perspectives share a common concern with the agecontext relativity of control judgements as well as their interaction with life domains and type of control judgement. From such a vantage point, one would not expect universal patterns of change across the lifespan. Instead, some domains should show gain (i.e. a greater personal control) and other domains should show losses depending on the life-task demands as well as the type of control judgement. These general assumptions on lifespan development are also reflected in other theories such as, for example, the age-related interplay between assimilative and accommodative coping strategies (Brandtstädter \& Renner, 1989), the age-related interplay between primary and secondary control (Heckhausen \& Schulz, 1995), and the age-related interplay between goals and control beliefs (Nurmi et al., 1992).

Notably, the majority of the trends across the three life domains showed variable trajectories that are quite consistent with such a perspective. For example, both goal importance and control striving showed variable and differentiating trends depending on the life domain that was assessed. In addition, many of the age-cohort trends within the same domain differed 
depending on the type of control judgement. Judgements in the societal domain were most notable in this regard: Control expectancy was low and decreased with age, whereas the importance of societal concerns was high and increased with age, and the degree of striving for control in the societal domain varied according to the life-phase of the participants (Fig. 2).

Of these metatheoretical perspectives, the modified life-task perspectives provide an encompassing framework for understanding the variability in the life course trajectories of control judgements. In our view, a next challenge for future research and theorising using such a framework will be to focus on more specific predictions regarding how, why, and when certain control judgements would increase while others would decrease, and still others would remain stable. In this regard, measures of life experiences, biophysical level, and other personal resources would help to guide such multiply specific hypotheses. Moreover, the interplay between control judgements and their role in regulating both performance and well-being (and vice versa) on an individual level needs to be more precisely explicated; so too do the possible effects of society and societal changes on individuals in general (Elder, 1994; Hagestad, 1990).

\section{Conclusions}

Given the variable and inconsistent findings that have been reported in the literature, this study has shed some new light on the multifaceted interplay between various control judgements and different life domains across the lifespan. We suggested that because of the domain specificity of control judgements, the various types of control constructs, and the breadth of the age-range examined, the apparently inconsistent findings might, in fact, be systematically interrelated. In this regard, we assumed that, by examining a broad age-range, the age trends of the various control judgements would differ (increase, decrease, and remain stable) meaningfully and systematically across life domains and type of construct.

The relations among the four control components were remarkably the same across the life domains and age-cohorts, indicating substantial stability and generalisability. At the same time, the relations between the sets of constructs provided considerable support for the domain specific nature of control judgements. Against the back-drop of these correlational patterns (i.e. within-domain stability and cross-domain specificity), the mean-level trends of the control constructs differed quite meaningfully and systematically across the lifespan. In our view, modified life-task perspectives, which emphasise the age-context relativity of control judgements, provide the most useful metatheoretical perspective for understanding the variable nature of these trends. However, future theorising about the lifespan development of control judgements must 
begin to provide more articulated statements about how, why, and when specific control judgements in specific life domains will change along the life course.

Manuscript received August 1997

Revised manuscript received March 1998

\section{REFERENCES}

Baltes, P.B. (1987). Theoretical propositions of life span developmental psychology: On the dynamics between growth and decline. Developmental Psychology, 23, 611-626.

Baltes, P.B., \& Baltes, M.M. (1990). Psychological perspectives on successful aging: The model of selective optimization with compensation. In P.B. Baltes \& M.M. Baltes (Eds.), Successful aging: Perspectives from the behavioral sciences (pp.1-34). New York: Cambridge University Press.

Baltes, P.B., Reese, H., \& Nesselroade, J.R. (1977). Life-span developmental psychology: Introduction to research methods. Hillsdale, NJ: Erlbaum.

Bandura, A. (1997). Self-efficacy. The exercise of control. New York, NY: Freeman.

Berry, J.M., \& West, R.L. (1993). Cognitive self-efficacy in relation to personal mastery and goal setting across the life span. International Journal of Behavioral Development, 16, 351379.

Berry, J.M., West, R.L., \& Dennehey, D. (1989). Reliability and validity of the Memory Self-Efficacy Questionnaire (MSEQ). Developmental Psychology, 25, 701-713.

Box, T.A., \& Peck, D.L. (1981). Perceived low self-actualization and external fatalistic determinism as a function of aging. Journal of Genetic Psychology, 139, 295-304.

Brandtstädter, J. (1997). Action perspectives on human development. In W. Damon \& R.M. Lerner (Eds.), Handbook of child psychology: Theoretical models of human development (4th ed.), (Vol. 1, pp.807-863). New York: Wiley.

Brandtstädter, J., Krampen, G., \& Heil, F.E. (1986). Personal control and emotional evaluation of development in partnership relations during adulthood. In M.M. Baltes \& P.B. Baltes (Eds.), The psychology of control and aging (pp.265-297). Hillsdale, NJ: Erlbaum.

Brandtstädter, J., \& Renner, G. (1989). Tenacious goal pursuit and flexible goal adjustment: Explication and age-related analysis of assimilative and accommodative strategies of coping. Psychology and Aging, 5, 58-67.

Brandtstädter, J. \& Rothermund, K. (1994). Self-precepts of control in middle and later adulthood: Buffering losses by rescaling goals. Psychology and Aging, 9, 265-273.

Carstensen, L.L. (1995). Evidence for a life-span theory of socioemotional selectivity. Current Directions, 4, 151-156.

Elder, G.H. Jr. (1994). Time, human agency, and social change: Perspectives on the life course. Social Psychology Quarterly, 57, 4-15.

Flammer, A. (1990). Erfahrung der eigenen Wirksamkeit: Einführung in die Psychologie der Kontrollmeinung [Experiencing self-efficacy: Introduction to the psychology of control beliefs]. Berlin: Huber.

Flammer, A., Grob, A., \& Lüthi, R. (1989). Swiss adolescents' attribution of control. In J.P. Forgas \& J.M. Innes (Eds.), Recent advances in social psychology (pp.81-94). Amsterdam: Elsevier.

Frese, M., \& Sabini, J. (Eds.). (1985). Goal-directed behavior: The concept of action in psychology. Hillsdale, NJ: Erlbaum. 
Grob, A. (1991). Meinung-Verhalten-Umwelt. Ein psychologisches Ursachennetz-Modell umweltgerechten Verhaltens [Belief-behavior-environment: A causal network model of environment appropriate behavior]. Bern: Lang.

Grob, A. (1995). A structural model of environmental attitudes and behavior. Journal of Environmental Psychology, 15, 209-220.

Grob, A., Flammer, A., \& Wearing, A.J. (1995). Adolescents' perceived control: Domain specificity, expectancy, and appraisal. Journal of Adolescence, 18, 403-425.

Grob, A., Little, T.D., Wanner, B., Wearing, A.J., \& Euronet (1996). Adolescents' wellbeing and perceived control across 14 sociocultural contexts. Journal of Personality and Social Psychology, 71, 785-795.

Hagestad, G.O. (1990). Social perspectives on the life course. In R. Binstock \& L. George (Eds.), Handbook of aging and the social sciences (3rd ed.) (pp.151-168). New York: Academic Press.

Havighurst, R.J. (1948). Developmental tasks and education. New York: McKay.

Heckhausen, H. (1991). Motivation and action. Berlin: Springer.

Heckhausen, J., Dixon, R.A., \& Baltes, P.B. (1989). Gains and losses in development throughout adulthood as perceived by different adult age groups. Developmental Psychology, 25, 109-121.

Heckhausen, J., \& Krueger, J. (1993). Developmental expectations for the self and most other people: Age grading in three functions of social comparison. Developmental Psychology, 29, 539-548.

Heckhausen, J., \& Schultz, R. (1995). A lifespan theory of control. Psychological Review, 102, 284-304.

Hertzog, C., Hultsch, D.F., \& Dixon, R.A. (1989). Evidence for the convergent validity of two self-report metamemory questionnaires. Developmental Psychology, 25, 687-700.

Jöreskog, K.G., \& Sörbom, D. (1989). LISREL 7: A guide to the program and applications. Chicago, IL: SPSS.

Kogan, N. (1990). Personality and aging. In J.E. Birren \& K.W. Schaie, K.W. (Eds.), Handbook of the psychology of aging (3rd ed.) (pp.330-346). San Diego: Academic Press.

Lachman, M.E. (1985). Personal efficacy in middle and old age: Differential and normative patterns of change. In G.H. Elder, Jr. (Ed.), Life-course dynamics: Trajectories and transitions, 1968-1980 (pp.188-213). Ithaca, NY: Cornell University Press.

Lachman, M.E. (1986). Locus of control in aging research: A case for multidimensional and domain-specific assessment. Journal of Psychology and Aging, 1, 34-40.

Lindenberger, U., \& Baltes, P.B. (1994). Sensory functioning and intelligence in old age: A strong connection. Psychology and Aging, 9, 339-355.

Little, T.D. (1997). Mean and covariance structures (MACS) analyses of cross-cultural data: Practical and theoretical issues. Multivariate Behavioral Research, 32, 53-76.

Little, T.D. (1998). Sociocultural influences on the development of children's action-control beliefs. In J. Heckhausen \& C.S. Dweck (Eds.), Motivation and self-regulation across the life span (pp.281-315). New York: Cambridge University Press.

Little, T.D., \& Lopez, D.F. (1997). Regularities in the development children's causal conceptions of school performance across six sociocultural contexts. Developmental Psychology, 33, 165-175.

Lumpkin, J.R. (1986). The relationship between locus of control and age: New evidence. Journal of Social Behavior and Personality, 1, 245-252.

Lüthi, R., Grob, A., \& Flammer, A. (1989). Differenzierte Erfassung bereichsspezifischer Kontrollmeinungen bei Jugendlichen [A differentiated conceptualisation of adolescents' domain specific control beliefs]. In G. Krampen (Ed.), Diagnostik von Attributionen und Kontrollüberzeugungen [Assessment of attributions and control beliefs] (pp.134-145). Göttingen: Hogrefe. 
Mayer, K.U. (1986). Structural constraints on the life course. Human Development, 29, 163170.

Molinari, V., \& Niederhe, G. (1984). Locus of control, depression, and anxiety in young and old adults: a comparison study. International Journal of Aging and Human Development, $20,41-52$.

Nehrke, M.F., Hulicka, I.H., \& Morganti, J. (1980). Age differences in life satisfaction, locus of control, and self-concept. International Journal of Aging and Human Development, 11, $25-33$.

Nurmi, J.-E. (1992). Age differences in adult life goals, concerns, and their temporal extension: A life course approach to future-oriented motivation. International Journal of Behavioral Development, 15, 487-508.

Nurmi, J.-E. (1994). The development of future orientation in a life-span context. In Z. Zaleski (Ed.), Psychology of future orientation (pp.63-74). Lublin: Naukowe KUL.

Nurmi, J.-E., Pulliainen, T., \& Salmela-Aro, K. (1992). Age differences in adult control beliefs related to life goals and concerns. Psychology and Aging, 7, 194-196.

Piaget, J. (1947). La psychologie de l'intelligence. Paris: Colin.

Rebok, G.W., \& Balcerak, L.J. (1989). Memory self-efficacy and performance differences in young and old adults: The effect of mnemonic training. Developmental Psychology, 25, 714-721.

Reker, G.T., Peacock, E.J., \& Wong, P.T.P. (1987). Meaning and purpose in life and wellbeing: A life span perspective. Journal of Gerontology, 42, 44-49.

Ryan, R.M., Sheldon, K.M., Kasser, T., \& Deci, E.L. (1996). All goals are not created equal: An organismic perspective on the nature of goals and their regulation. In P.M. Gollwitzer \& J.A. Bargh (Eds.), The psychology of action: Linking motivation and cognition to behavior. New York: Guilford Press.

Salthouse, T.A. (1991). Theoretical perspectives on cognitive aging. Hillsdale, NJ: Erlbaum. Siegler, I.C., \& Gatz, M. (1985). Age patterns in locus of control. In E. Palmore, J. Nowlin, E. Busse, I.C. Siegler, \& G. Maddox, (Eds.), Normal aging: III (pp.259-267). Durham, NC: Duke University Press.

Skinner, E.A. (1995). Perceived control, motivation, and coping. Beverly Hills, CA: Sage.

Skinner, E.A. (1996). A guide to constructs of control. Journal of Personality and Social Psychology, 71, 549-570.

Taylor, S.E., \& Brown, J.D. (1994). Positive illusions and well-being revisited: Separating fact from fiction. Psychological Bulletin, 116, 21-27.

Welch, D.C., \& West, R.L. (1995). Self-efficacy and mastery: Its application to issues of environmental control, cognition, and aging. Developmental Review, 15, 150-171.

White, R.W. (1959). Motivation reconsidered: The concept of competence. Psychological Review, 66, 297-333. 